\title{
Magnitude and distance distribution of strong aftershocks in Sichuan-Yunnan region*
}

\author{
LÜ Xiao-jian ${ }^{1,2), `}$ (吕晓健) GAO Meng-tan ${ }^{1)}$ (高孟潭) GAO Zhan-wu ${ }^{2)}$ (高战武) \\ MI Su-ting ${ }^{2)}$ (米素婷) \\ 1) Institute of Geophysics, China Earthquake Administration, Beijing 100081, China \\ 2) Institute of Earthquake Science, China Earthquake Administration, Beijing 100036, China
}

\begin{abstract}
Using the earthquake sequences data with $M_{\mathrm{S}} \geq 6.5$ since 1966 in Sichuan-Yunnan region, we research the characteristic of the magnitude difference distribution between main shocks and their strong aftershocks; and then study the spatial distribution characteristic of the strong aftershocks away from their main shocks. The result shows that the magnitude difference distribution obeys intercepted exponential distribution, while the spatial distribution of strong aftershocks obeys normal distribution and the dominated distribution area of strong shocks is 10 39 km away from main shock. Finally the probability density function of the magnitude difference distribution and the spatial distribution of strong aftershocks is deduced.
\end{abstract}

Key words: Sichuan-Yunnan region; strong aftershock; magnitude difference distribution; spatial distribution CLC number: P315. $3^{+} 2 \quad$ Document code: A

\section{Introduction}

Sichuan-Yunnan region is connection area of the northeastern boundary of India Plate and Eurasian Plate; it is also the transition area from the southeast of Qinghai-Tibet Plateau to the Yunnan Plateau. The neotectonic movement in Sichuan-Yunnan region is very active, which results in a number of large earthquakes. Since 1900, there have been 21 large earthquakes with $M_{\mathrm{S}} \geq 7$ occurred in Sichuan-Yunnan region, the interval time of the large earthquakes is short and the magnitude is high, therefore seismic design should be paid attention to during important construction project. There have been eight $M_{\mathrm{S}} \geq 7$ earthquakes occurred in Sichuan-Yunnan region since 1970, of which seven have strong aftershocks with $M_{\mathrm{S}} \geq 5$; three are multi-earthquake style with more than two strong aftershocks and its magnitude close to the main shock (WU et al, 1990), showing active strong aftershocks. Effective peak acceleration (EPA) maybe exceeds the EPA generated by main shock when strong aftershock is far away from the main shock (LÜ et al, 2007). Seismic design may be unsafe and unreasonable due to not taking the influence of the strong aftershock into account in probability seismic hazard analysis (PSHA) in China. In this paper, we study the characteristic of magnitude difference distribution between main shock and their strong

\footnotetext{
* Received 2007-12-25; accepted in revised form 2008-06-05

Foundation item: Basic research program from Institute of Earthquake Science China Earthquake Administration (690206) and Social Welfare Research Program from Ministry of Science and Technology of China (2005DIB3J119).

Contribution No.08FE3009, Institute of Geophysics, China Earthquake Administration.

^ Author for correspondence: 1xj@seis.ac.cn
} 
aftershocks, as well as spatial distribution characteristic of strong aftershocks away from their main shocks, and then construct the probability model of magnitude difference distribution and spatial distribution of strong aftershocks. The result is helpful in PSHA to reasonably considering influence of strong aftershocks and providing more scientific seismic design demand for important construction project in Sichuan-Yunnan region.

\section{Data}

Since the Xingtai earthquake occurred on March 8, 1966, seismic networks construction in China develops rapidly and thus a great number of seismic data were recorded. There have been 30 $M_{\mathrm{S}} \geq 6$ earthquakes occurred in Sichuan-Yunann region during the period from 1966 to 2007, of which 11 earthquakes with $M_{\mathrm{S}} 6.0 \sim 6.4,11$ earthquakes with $M_{\mathrm{S}} 6.5 \sim 6.9$ and eight earthquakes with $M_{\mathrm{S}} \geq 7.0$. If we select the largest aftershock as research data, the number of data is too little. To ensure enough data number, we select all of strong aftershocks with $M_{\mathrm{S}} \geq 5$ as research data. In this paper, we define the largest shock as the main shock of the main-aftershock style earthquake sequence and the first large shock as the main shock of the multi-earthquake style earthquake sequence.

The select principle of strong aftershocks is as follows. (1) Studies have shown that the spatial distribution of earthquake sequence is gradually stable 30 days after main shock, afterwards the scope of spatial distribution vary little (Henry and Das, 2001). In order to sufficiently use the aftershocks data and obtain reliable spatial distribution of strong aftershocks, we select aftershock spatial region three months after $M_{\mathrm{S}} \geq 6$ earthquake as the aftershock zone to select strong aftershocks in the aftershock zone. The aftershocks data are from the earthquake sequence catalog compiled by JIAO et al (2006). (2) The end time of earthquake sequences are chosen as that when the frequency of $M_{\mathrm{L}} \geq 3$ earthquake in the aftershock zone is as low as that before the main shock, that is the time window of selecting strong aftershocks. The earthquake data with $M_{\mathrm{L}} \geq 3$ come from the Chinese Small Earthquake Catalog (https://baseapnet.seis.ac.cn) compiled by China Earthquake Networks Center. The strong aftershocks data come from The Catalog of Chinese Present Strong Earthquake (AD 1912 1990, $M_{\mathrm{S}} \geq 4.7$ ) (WANG et al, 1999), Earthquake Cases in China (1995 1996) (CHEN et al, 2002) and Fast Report Earthquake Catalogue compiled by China Earthquake Networks Center (https://baseapnet.seis.ac.cn).

Through statistic analysis of 30 earthquake sequences with $M_{\mathrm{S}} \geq 6$ since 1966, we find that two earthquakes with $M_{\mathrm{S}} 6.0 \sim 6.4$ have one strong aftershock, five earthquakes with $M_{\mathrm{S}} 6.5 \sim 6.9$ have 21 strong aftershocks and seven earthquakes with $M_{\mathrm{S}} \geq 7$ have 54 strong aftershocks. Due to the number of the strong aftershock is few after the main earthquake with $M_{\mathrm{S}} 6.0 \sim 6.4$, we select the strong aftershocks of earthquake sequence with $M_{\mathrm{S}} \geq 6.5$ as our research data, and then establish the strong aftershock catalog of Sichuan-Yunnan region according to the select principle of the strong aftershocks. Using the strong aftershock catalog, we statistically analyze the magnitude difference distribution between the main shocks and the strong aftershocks and spatial distribution characteristic of aftershocks (Table1). Figure 1 shows the spatial distributions of the main shocks and their strong aftershocks of 12 earthquake sequences with $M_{\mathrm{S}} \geq 6.5$

\section{Magnitude distribution charac ter of strong aftershock}

Table 1 lists the magnitude difference between the main shocks and their strong aftershocks and the distance of the strong aftershock to its main shock. From Table 1 we can see the multi- 
Table 1 Strong aftershock catalog of Sichuan-Yunnan region

\begin{tabular}{|c|c|c|c|c|c|c|c|}
\hline $\begin{array}{c}\text { No. of } \\
\text { sequence }\end{array}$ & $\begin{array}{l}\text { Earthquake } \\
\text { sequence }\end{array}$ & $\begin{array}{c}\text { Date } \\
\text { a-mo-d }\end{array}$ & $\varphi_{\mathrm{N}} /^{\circ}$ & $\lambda_{\mathrm{E}} /^{\circ}$ & Magnitude & $\begin{array}{l}\text { Magnitude } \\
\text { difference }\end{array}$ & Distance $/ \mathrm{km}$ \\
\hline \multirow{6}{*}{1} & \multirow{6}{*}{ Dongchuan } & 1966-02-05 & 26.2 & 103.20 & 6.5 & & \\
\hline & & 1966-02-06 & 26.0 & 103.10 & 5.0 & 1.5 & 24 \\
\hline & & 1966-02-06 & 26.5 & 103.00 & 5.3 & 1.2 & 39 \\
\hline & & $1966-02-06$ & 26.0 & 103.18 & 5.2 & 1.3 & 22 \\
\hline & & $1966-02-13$ & 26.1 & 103.10 & 6.2 & 0.3 & 15 \\
\hline & & 1966-12-18 & 26.1 & 103.20 & 5.2 & 1.3 & 11 \\
\hline \multirow{2}{*}{2} & \multirow{2}{*}{ Luhuo } & $1967-08-30$ & 31.62 & 100.33 & 6.8 & & \\
\hline & & $1967-08-30$ & 31.70 & 100.67 & 6.0 & 0.8 & 34 \\
\hline \multirow{5}{*}{3} & \multirow{5}{*}{ Yanyuan } & 1976-11-07 & 27.45 & 101.08 & 6.7 & & \\
\hline & & 1976-11-07 & 27.50 & 101.10 & 5.6 & 1.1 & 6 \\
\hline & & 1976-11-07 & 27.40 & 101.20 & 5.1 & 1.5 & 13 \\
\hline & & $1976-12-13$ & 27.32 & 101.50 & 6.4 & 0.3 & 15 \\
\hline & & $1976-12-13$ & 27.30 & 101.00 & 5.0 & 1.7 & 18 \\
\hline \multirow{7}{*}{4} & \multirow{7}{*}{ Batang } & 1989-04-16 & 29.99 & 99.23 & 6.6 & & \\
\hline & & 1989-04-25 & 30.05 & 99.42 & 6.6 & 0 & 18 \\
\hline & & 1989-05-01 & 30.04 & 99.47 & 5.2 & 1.4 & 29 \\
\hline & & 1989-05-03 & 30.11 & 99.54 & 6.3 & 0.3 & 38 \\
\hline & & 1989-05-03 & 30.07 & 99.55 & 6.3 & 0.3 & 39 \\
\hline & & $1989-5-4$ & 30.07 & 99.45 & 5.1 & 1.5 & 29 \\
\hline & & 1989-7-21 & 29.99 & 99.49 & 5.1 & 0.7 & 29 \\
\hline \multirow{6}{*}{5} & \multirow{6}{*}{ Wuding } & 1995-10-24 & 25.90 & 102.20 & 6.5 & & \\
\hline & & $1995-10-25$ & 25.90 & 102.30 & 5.1 & 1.4 & 10 \\
\hline & & $1995-10-25$ & 25.90 & 102.20 & 5.0 & 1.5 & 0 \\
\hline & & $1995-10-25$ & 25.90 & 102.20 & 5.0 & 1.5 & 0 \\
\hline & & $1995-10-25$ & 25.90 & 102.20 & 5.0 & 1.5 & 0 \\
\hline & & 1995-11-01 & 25.70 & 102.20 & 5.1 & 1.4 & 22 \\
\hline \multirow{10}{*}{6} & \multirow{10}{*}{ Tonghai } & 1970-01-05 & 24.00 & 102.70 & 7.8 & & \\
\hline & & $1970-01-05$ & 24.20 & 102.50 & 5.2 & 2.6 & 30 \\
\hline & & $1970-01-05$ & 24.25 & 102.53 & 5.5 & 2.3 & 32 \\
\hline & & $1970-01-05$ & 24.07 & 103.08 & 5.9 & 1.9 & 40 \\
\hline & & $1970-01-05$ & 24.08 & 102.68 & 5.3 & 2.5 & 9 \\
\hline & & 1970-01-09 & 24.12 & 102.98 & 5.0 & 2.8 & 31 \\
\hline & & $1970-01-14$ & 24.30 & 102.75 & 5.4 & 2.0 & 33 \\
\hline & & $1970-02-05$ & 24.28 & 102.37 & 5.7 & 2.1 & 46 \\
\hline & & $1970-03-11$ & 23.93 & 103.08 & 5.2 & 2.6 & 39 \\
\hline & & 1970-03-13 & 24.02 & 102.95 & 5.9 & 1.9 & 25 \\
\hline \multirow{4}{*}{7} & \multirow{4}{*}{ Luhuo } & 1973-02-06 & 31.48 & 100.56 & 7.6 & & \\
\hline & & $1973-02-06$ & 31.30 & 100.70 & 5.0 & 2.6 & 26 \\
\hline & & $1973-02-07$ & 31.40 & 100.90 & 5.0 & 2.6 & 36 \\
\hline & & 1973-02-08 & 31.60 & 100.50 & 6.0 & 1.6 & 13 \\
\hline \multirow{4}{*}{8} & & 1974-05-11 & 28.20 & 103.90 & 7.1 & & \\
\hline & & 1974-06-05 & 28.30 & 104.20 & 5.0 & 2.1 & 31 \\
\hline & Zhaotong & $1974-06-15$ & 28.40 & 104.20 & 5.7 & 1.4 & 37 \\
\hline & & 1974-06-15 & 28.30 & 104.10 & 5.2 & 1.9 & 22 \\
\hline & & 1976-05-29 & 24.50 & 99.00 & 7.3 & & \\
\hline & & $1976-05-29$ & 24.50 & 98.80 & 5.1 & 2.2 & 20 \\
\hline & & $1976-05-29$ & 24.45 & 98.87 & 7.4 & -0.1 & 14 \\
\hline & & $1976-05-29$ & 24.50 & 98.70 & 5.2 & 2.1 & 30 \\
\hline & & $1976-05-30$ & 24.60 & 98.80 & 5.7 & 1.6 & 23 \\
\hline & & $1976-05-30$ & 24.40 & 98.80 & 5.6 & 1.7 & 23 \\
\hline & & $1976-05-31$ & 24.60 & 98.80 & 5.2 & 2.1 & 23 \\
\hline 0 & & $1976-05-31$ & 24.20 & 98.70 & 6.5 & 0.8 & 45 \\
\hline 9 & Longling & $1976-06-01$ & 24.20 & 98.70 & 6.0 & 1.3 & 45 \\
\hline & & 1976-06-09 & 24.20 & 98.70 & 5.0 & 2.3 & 45 \\
\hline & & 1976-06-09 & 24.88 & 98.70 & 6.2 & 1.1 & 52 \\
\hline & & $1976-06-20$ & 24.50 & 98.63 & 5.1 & 2.2 & 37 \\
\hline & & 1976-07-04 & 24.30 & 98.80 & 6.0 & 1.3 & 30 \\
\hline & & $1976-07-21$ & 24.8 & 98.70 & 6.6 & 0.7 & 52 \\
\hline & & $1976-07-23$ & 24.9 & 98.70 & 5.5 & 1.8 & 54 \\
\hline & & 1976-08-02 & 24.82 & 98.60 & 5.0 & 2.3 & 54 \\
\hline
\end{tabular}


Continued from Table 1

\begin{tabular}{|c|c|c|c|c|c|c|c|}
\hline $\begin{array}{c}\text { No. of } \\
\text { sequence }\end{array}$ & $\begin{array}{l}\text { Earthquake } \\
\text { sequence }\end{array}$ & $\begin{array}{c}\text { Date } \\
\text { a-mo-d }\end{array}$ & $\varphi_{\mathrm{N}} /^{\circ}$ & $\lambda_{\mathrm{E}} /^{\circ}$ & Magnitude & $\begin{array}{l}\text { Magnitude } \\
\text { difference }\end{array}$ & Distance $/ \mathrm{km}$ \\
\hline \multirow{7}{*}{10} & \multirow{7}{*}{ Songpan } & $1976-08-16$ & 32.61 & 104.13 & 7.2 & & \\
\hline & & $1976-08-16$ & 32.50 & 104.60 & 5.0 & 2.2 & 46 \\
\hline & & 1976-08-19 & 32.90 & 104.30 & 5.9 & 1.3 & 35 \\
\hline & & $1976-08-22$ & 32.60 & 104.40 & 6.7 & 0.5 & 26 \\
\hline & & $1976-08-23$ & 32.50 & 104.30 & 7.2 & 0 & 21 \\
\hline & & 1976-09-01 & 32.50 & 104.10 & 5.1 & 2.1 & 13 \\
\hline & & 1976-09-21 & 32.80 & 104.20 & 5.2 & 2.0 & 21 \\
\hline \multirow{14}{*}{11} & \multirow{14}{*}{$\begin{array}{l}\text { Lancang } \\
\text {-Gengma }\end{array}$} & 1988-11-6 & 22.92 & 99.75 & 7.4 & & \\
\hline & & 1988-11-06 & 23.37 & 99.50 & 7.2 & 0.2 & 58 \\
\hline & & 1988-11-06 & 22.87 & 99.67 & 5.7 & 1.7 & 10 \\
\hline & & 1988-11-06 & 23.24 & 99.64 & 5.5 & 1.9 & 38 \\
\hline & & 1988-11-06 & 23.29 & 99.55 & 5.2 & 2.2 & 46 \\
\hline & & 1988-11-07 & 23.37 & 99.52 & 5.4 & 2 & 56 \\
\hline & & 1988-11-07 & 23.03 & 99.81 & 5.6 & 1.8 & 14 \\
\hline & & 1988-11-07 & 23.36 & 99.37 & 5.0 & 2.4 & 63 \\
\hline & & 1988-11-07 & 23.46 & 99.54 & 5.3 & 2.1 & 64 \\
\hline & & 1988-11-15 & 23.18 & 99.71 & 5.6 & 1.8 & 30 \\
\hline & & $1988-11-27$ & 22.74 & 99.94 & 5.8 & 1.6 & 27 \\
\hline & & 1988-11-30 & 22.76 & 99.95 & 6.5 & 0.9 & 27 \\
\hline & & 1988-12-08 & 23.40 & 99.56 & 5.1 & 2.3 & 58 \\
\hline & & 1988-12-19 & 23.30 & 99.57 & 5.3 & 2.1 & 46 \\
\hline \multirow{5}{*}{12} & \multirow{5}{*}{ Lijiang } & 1996-02-03 & 27.20 & 100.30 & 7.0 & & \\
\hline & & 1996-02-05 & 27.00 & 100.30 & 6.0 & 1.0 & 22 \\
\hline & & 1996-02-06 & 27.10 & 100.40 & 5.6 & 1.4 & 14 \\
\hline & & 1996-02-07 & 27.20 & 100.30 & 5.3 & 1.7 & 0 \\
\hline & & 1996-02-07 & 27.10 & 100.20 & 5.1 & 1.9 & 14 \\
\hline
\end{tabular}

earthquake style sequence occupies high proportion in Sichuan Yunnan region. There are six earthquake sequences belonging to multi-earthquake style. These six earthquake sequences include 1966 Dongchuan $M_{\mathrm{S}} 6.5$ earthquake, 1976 Yanyuan $M_{\mathrm{S}} 6.7$ earthquake, 1989 Batang $M_{\mathrm{S}} 6.6$ earthquake, 1976 Longling $M_{\mathrm{S}} 7.3$ earthquake, 1976 Songpan $M_{\mathrm{S}} 7.2$ earthquake and $1988 M_{\mathrm{S}} 7.4$ Lancang-Gengma earthquake. The multi-earthquake style earthquake sequence occupies $27 \%$ of the total earthquake sequence with $M_{\mathrm{S}} 6.5 \sim 6.9$ and $38 \%$ of the earthquake sequence with $M_{\mathrm{S}} \geq 7$, namely, one third of earthquake sequences with $M_{\mathrm{S}} \geq 6.5$ is multi-earthquake style, of which three sequences have strong aftershock with magnitude equal to or greater than main earthquake. In addition, the strong aftershock frequency of the multi-earthquake style earthquake sequence is obvious higher than other style earthquake sequence (Table 1).

From Table 1 we can find that there are average four strong aftershocks after main shock with $M_{\mathrm{S}} 6.5 \sim 6.9$ and eight strong aftershocks after main shock with $M_{\mathrm{S}} \geq 7$. The strong aftershock frequency of main shock with $M_{\mathrm{S}} \geq 7$ is higher than that of main shock with $M_{\mathrm{S}} 6.5 \sim 6$.9. The magnitude difference is from -0.1 to 2.8 between 75 strong aftershocks and their main shocks. Considering the monitoring capacity, we take interval magnitude 0.3 to statistically analyze the magnitude difference distribution character. Figure 2 is the histogram of the magnitude difference distribution. From Figure 2, it can be seen that the abscissa of maximal frequency is near 1.5; of course the result is partial related to selecting aftershock with $M_{\mathrm{S}} \geq 5$ as research data. The statistic analysis shows the probability is 0.04 for magnitude difference $\Delta M \leq 0.1,0.11$ for $\Delta M \leq 0.4,0.15$ for $\Delta M \leq 0.7$ and 0.2 for $\Delta M \leq 1$.

We find the magnitude difference obeys exponential distribution when $\Delta M \leq 1.5$, the formula is

$$
\log N=a+b \Delta M
$$




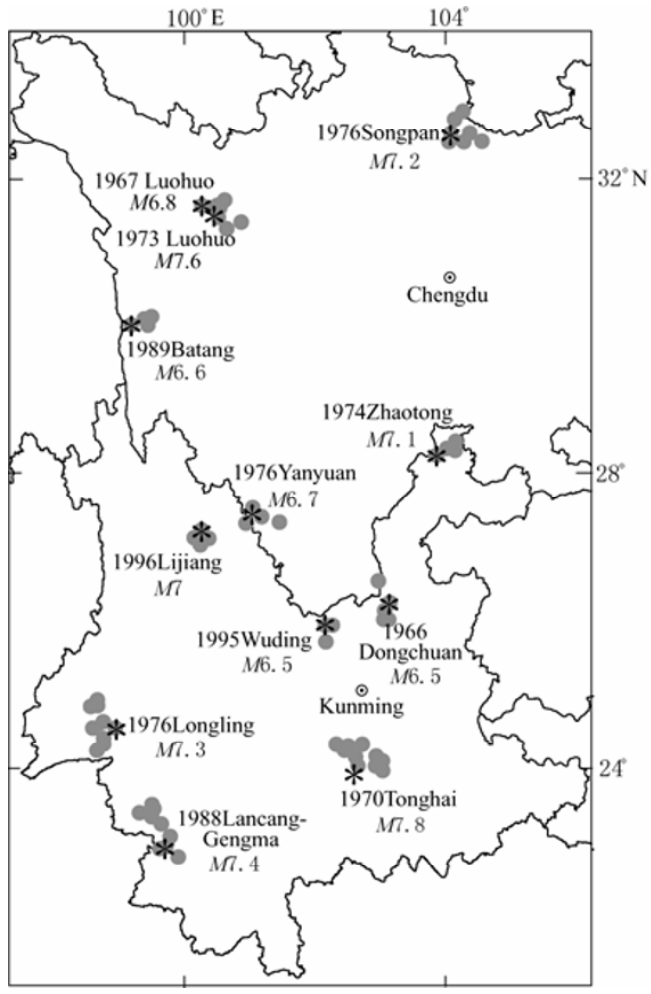

Figure 1 Distribution of earthquake sequence *: mainshock; $\bullet$ : strong aftershock

Since the relation between aftershock magnitude and accumulative total frequency obeys N-B relation, the magnitude difference between strong aftershocks and their main shocks with their accumulated frequency is subjected to N-B relations naturally. Using the least square method to fit the formula (1), we can get the coefficients: $a=0.5904 \pm 0.0623, b=0.6634 \pm 0.0685$, the correlation coefficient 0.9793 and the variance 0.0860 .

Because we have defined the lowest magnitude of the strong aftershocks and usually the magnitude of the strong aftershocks is not more than the magnitude of their main shocks, the magnitude difference between the strong aftershocks and their main shocks and the accumulative total frequency obeys the intercepted exponential distribution, the corresponding probability density function is

$$
f_{\Delta M}(\Delta M)=\frac{\beta \exp \left[-\beta\left(\Delta M-\Delta M_{0}\right)\right]}{1-\exp \left[-\beta\left(\Delta M_{\mathrm{u}}-\Delta M_{0}\right)\right]}
$$

In the equation, $\Delta M$ is the magnitude difference, $\Delta M_{0}$ is the minimal magnitude difference, $\Delta M_{\mathrm{u}}$ is the maximal magnitude difference, $\beta=b \times \ln 10$, for Sichuan-Yunnan region $\beta$ $=1.5275$, we can get the strong aftershock's probability of different magnitude segment in Sichuan-Yunnan region by calculating the integral of the equation (2).

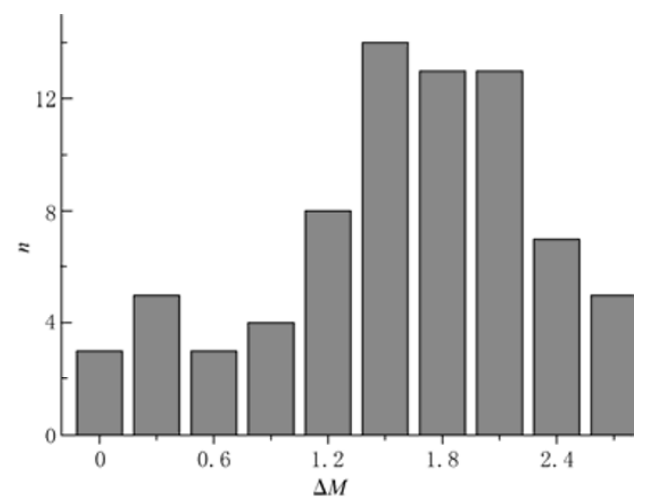

Figure 2 Distribution of the magnitude difference between main shocks and strong aftershocks

$x$-axis is the difference, $y$-axis is the number of the difference

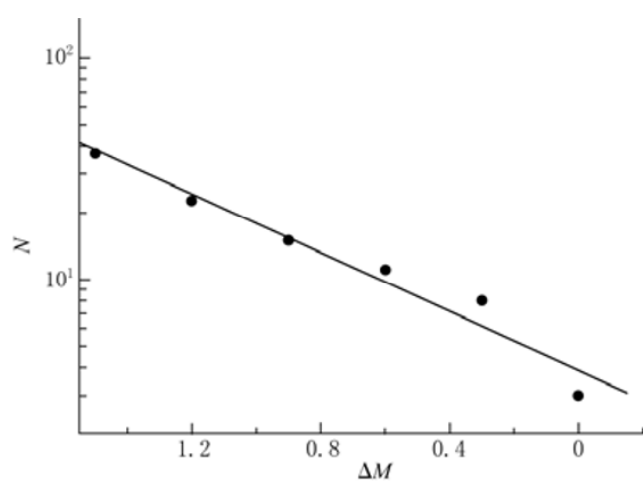

Figure 3 Fitting plot of the magnitude difference between main shocks and strong aftershocks with the accumulation number 


\section{Spatial distribution characte of the strong aftershock}

Many seismologist have studied the aftershock spatial distribution character, although using different data, they get similar conclusion, that is, spatial distribution scale has positive correlation with the main shock magnitude; the bigger the main shock's magnitude, the larger the aftershock's spatial distribution area (Utsu, 1961; WU et al, 1990; JIANG et al, 2007). If the strong aftershock frequency is high, the spatial distribution scale of strong aftershocks will be close to the scale of all of the aftershocks (LÜ et al, 2007). By analyzing above-mentioned research results, we can know the probable area of strong aftershock, but it is too conservative if using maximal distance to consider strong aftershock's influence in PSHA. In order to reasonably consider the strong aftershock's influence in PSHA, in this paper we study the spatial distribution character of the strong aftershocks.

From Table 1 we can see the nearest distance is $0 \mathrm{~km}$ and the farthest distance is $63 \mathrm{~km}$ between the 12 main shocks and their 75 strong aftershocks. Considering the earthquake monitoring capacity of Sichuan-Yunnan region, using $5 \mathrm{~km}$ as the interval to analyze the distance distribution, the result shows most strong aftershocks occurred at 10 39 km away from their main shocks. The probability is 0.9 occurred within the distance equal to or greater than $10 \mathrm{~km}$, thereinto the probability is respectively $0.2,0.23,0.24$ and 0.24 when the distance is from $10 \mathrm{~km}$ to $19 \mathrm{~km}, 20 \mathrm{~km}$ to $29 \mathrm{~km}, 30 \mathrm{~km}$ to $39 \mathrm{~km}$, and the earthquakes occurred within distance equal to or greater than 40 $\mathrm{km}$ is strong aftershock of large earthquake with $M_{\mathrm{S}} \geq 7$. By describing the distance and its' probability on the coordinates, we can find the probability maybe obey the normal distribution (Figure 4). Supposing the probability distribution of the distance obeys the normal distribution $N(\mu, \sigma)$, its probability density function is

$$
f_{(x)}=\frac{1}{\sqrt{2 \pi}} \mathrm{e}^{-\frac{(x-\mu)^{2}}{2 \sigma^{2}}}
$$

Using the maximum likelihood method to fit equation (3), we can obtain the parameter $\mu=28$, $\sigma=16$. By calculating the integral of the equation (3), we can get the strong aftershock probability of the different distance away from its main shock in Sichuan-Yunnan region.

In order to verify whether the distance between the main earthquakes and their strong aftershocks obeys to normal distribution, we use the normal distribution probability map method to the test it (LIANG, 2000). The abscissa of the normal distribution probability map is even scale and the ordinate is even scale according to the $\mathrm{p}$ quantile of the standard normal distribution. The coordinate axis system makes the function of the normal distribution to be a straight line. According to declining gradation, we arrange the probability distribution value as $P_{(1)} \leq P_{(2)} \leq \cdots \leq P_{(n)}$, and then plot the number pair $\left(P_{(k)}, \frac{k-3 / 8}{n+1 / 4}\right)(k=1,2 \cdots n)$ on the normal distribution probability map. From Figure 5, we can see these points locate near a straight line, so it can roughly be thought that the distance distribution obeys normal distribution.

\section{Discussion and conclusions}

According to our statistic analysis of the 75 strong aftershocks of 12 earthquake sequences with $M_{\mathrm{S}} \geq 6.5$ since 1966 in Sichuan-Yunnan region, we obtain the following conclusions: 


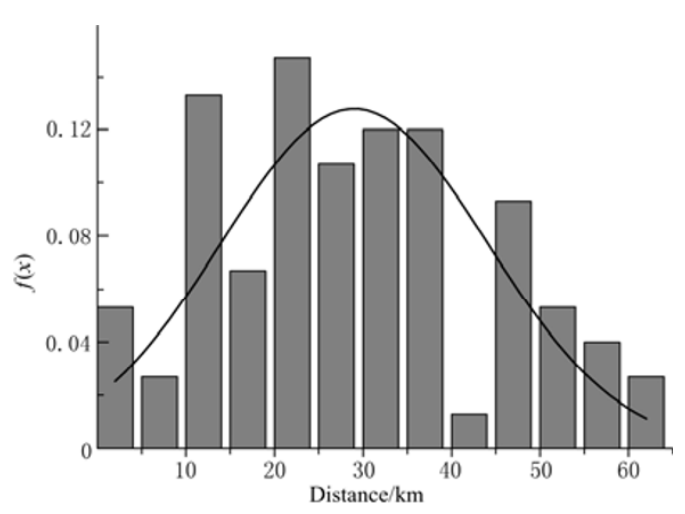

Figure 4 Probability distribution of the distance between main shocks and their strong aftershocks

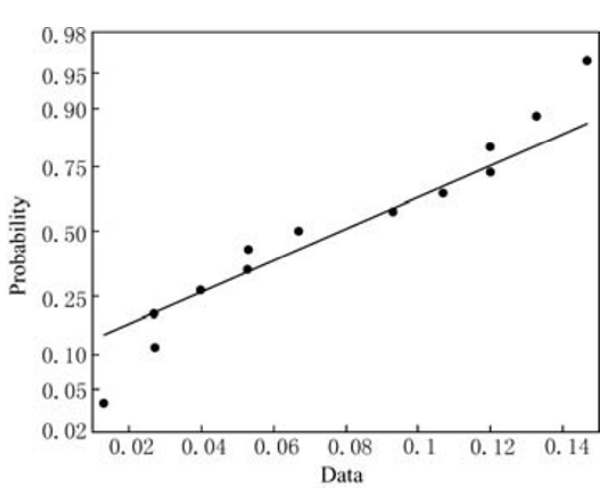

Figure 5 Normal distribution probability plot of the distance between main shocks and strong aftershocks

1) It is very high of the frequency and the magnitude of the strong aftershocks after every main shock with $M_{\mathrm{S}} \geq 6.5$ in Sichuan-Yunnan region. The relation of the cumulative frequency with magnitude difference between the main shocks and their strong aftershocks obeys the interrupted exponential distribution.

2) $10 \sim 39 \mathrm{~km}$ is the predominant distance between the strong aftershocks and their main shocks.

3) The spatial distribution of the strong aftershock obeys the normal distribution. By fitting data, we obtain the magnitude distribution probability density function and spatial distribution probability density function of the strong aftershock in Sichuan-Yunnan region. By calculating the integral of the probability density function we can get the probability value.

The strong aftershock has some characteristics in Sichuan-Yunnan region, such as the high magnitude, the high frequency and far away from its main shock. The strong aftershock far away from its main shock always generates more serious damage than the main shock near the strong aftershock epicenter, so the influence of strong aftershock must be considered in PSHA for the major projects. When the ground motion generated by the main shock is lower than the design ground motion, we should consider the ground motion generated by the strong aftershock whether exceed the design ground motion. According to this paper's result, we can get the probability of the strong aftershock's location and magnitude to calculate the ground motion generated by the strong aftershock. The seismic design will be more reasonable and safe if we take into account the influence of the strong aftershock, and the phenomena can be avoided that the strong aftershock causes more serious damage than the main shock. This paper's results provide foundation for reasonable considering the strong aftershock influence in PSHA for the major project in Sichuan-Yunnan region.

However, due to data constraints, the results of the study are also a little rough. For example, it can be seen from Table 1, the strong aftershock magnitude and frequency of the different style earthquake sequence has obvious difference, the multi-earthquake style earthquake sequence has more strong aftershocks and the spatial distribution scale of the strong aftershock is larger than other style earthquake sequence. In different seismotectonic province, the style of the earthquake sequence has obvious difference; the earthquake sequence is generally mainshock-aftershock sequence style in Chuan-Dian rhombic block, nearby Simao and Puer. The earthquake sequence 
generally is the multi-earthquake style nearby Xiaguan, Yao'an, Longling, Lancang, Ludian, Yanyuan, Batang, Mabian, Songpan-Longmenshan (JIANG et al, 2006). Due to earthquake sequence has characters above-mentioned, if the data is enough we should study the magnitude distribution and spatial distribution probability model for different style earthquake sequence respectively. The data will be enriched gradually in future, we can refine and perfect our study step by step so that the seismic risk analysis results will become more reliable and more secure.

\section{References}

CHEN Qi-fu, ZHENG Da-lin, LIU Gui-ping, et al. 2002. Earthquake Cases in China (1995 1996) [M]. Beijing: Seismological Press: 97-429 (in Chinese)

China Earthquake Networks Center. 2006. The catalog of earthquake quick report (2000 2002) [G/OL]. (2008-07-01) [2007-10-05]. [http://www.csndmc.ac.cn/newweb/data.htm.

Henry C and Das S. 2001. Aftershock zone of larger shallow earthquake: Fault dimension, aftershock area expansion and scaling relation [J]. Geophys J Int, 147: 272-293.

JIANG Hai-kun, LI Yong-li, QU Yan-jun, et al. 2006. Spatial distribution features of sequence types of moderate and strong earthquake in Chinese mainland [J]. Acta Seismologica Sinica, 19(4): 417-427.

JIANG Hai-kun, ZHENG Jian-chang, WU Qiong et al. 2007. Statistical features of aftershock distribution size for moderate and large earthquake in Chinese mainland [J]. Acta Seismologica Sinica, 20(2): 158-171.

JIAO Yuan-bi, PENG Ke-yin, CHEN Rong-hua, et al. 2006. Earthquake sequence catalog (1966 2002) [G/OL]. (2006-10-01) [2007-10-05]. http://www-wdeds.seis.ac.cn/cn/xl/xl.htm.

LIANG Xiao-jun. 2000. Normal inspection (1) [J]. Shanghai Statistics, 10: 22-25.

LÜ Xiao-jian, GAO Meng-tan, GAO Zhan-wu, et al. 2007. Comparison of the spatial distribution of ground motion between main shocks and strong aftershocks [J]. Acta Seismologica Sinica, 20(3): 312-318.

Ustu T A. 1961. Statistical study on the occurrence of aftershocks [J]. Geophys Mag, 30: 521-605.

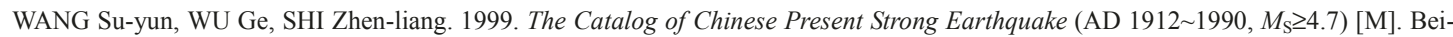
jing: China Science and Technology Press: 172-439 (in Chinese).

WU Kai-tong, JIAO Yuan-bi, LÜ Pei-ling, et al. 1990. Research on Earthquake Sequence [M]. Beijing: Peking University Press: 97-118 (in Chinese). 